Revista de Metalurgia 51(1)

January-March 2015, e034

ISSN-L: 0034-8570

doi: http://dx.doi.org/10.3989/revmetalm.034

\title{
Small punch creep test in a 316 austenitic stainless steel
}

\author{
Maribel L. Saucedo-Muñoz ${ }^{\mathrm{a}, \varpi}$, Shi-Ichi Komazaki ${ }^{\mathrm{b}}$, Toshiyuki Hashida ${ }^{\mathrm{c}}$, Víctor M. López-Hirata ${ }^{\mathrm{a}}$ \\ ${ }^{a}$ Instituto Politécnico Nacional (ESIQIE), Apartado Postal 118-556, México D.F. 07300, México \\ ${ }^{b}$ University of Kagoshima, Faculty of Engineering, Korimoto Kagoshima 890, Japan \\ ${ }^{c}$ Tohoku University, School of Engineering, Aobayama, Sendai 980, Japan \\ corresponding author: maribelsaucedo@prodigy.net.mx
}

Submitted: 4 September 2014; Accepted: 10 November 2014; Available On-line: 25 F ebruary 2015

\begin{abstract}
The small punch creep test was applied to evaluate the creep behavior of a 316 type austenitic stainless steel at temperatures of 650,675 and $700{ }^{\circ} \mathrm{C}$. The small punch test was carried out using a creep tester with a specimen size of $10 \times 10 \times 0.3 \mathrm{~mm}$ at 650,675 and $700{ }^{\circ} \mathrm{C}$ using loads from 199 to $512 \mathrm{~N}$. The small punch creep curves show the three stages found in the creep curves of the conventional uniaxial test. The conventional creep relationships which involve parameters such as creep rate, stress, time to rupture and temperature were followed with the corresponding parameters of small punch creep test and they permitted to explain the creep behavior in this steel. The mechanism and activation energy of the deformation process were the grain boundary sliding and diffusion, respectively, during creep which caused the intergranular fracture in the tested specimens.
\end{abstract}

KEYWORDS: 316 Austenitic stainless steel; Creep behavior; Small punch creep test

Citation / Cómo citar este artículo: Saucedo-Muñoz, M.L., Komazaki, S., Hashida, T., López-Hirata, V.M. (2015) “Small punch creep test in a 316 austenitic stainless steel". Rev. Metal. 51(1): e034. doi: http://dx.doi.org/10.3989/revmetalm.034.

RESUMEN: Ensayo de termofluencia de indentación en un acero inoxidable austenítico 316. El ensayo de termofluencia por indentación se utilizó para evaluar el comportamiento a la termofluencia en un acero inoxidable austenítico 316. Este ensayo se realizó en una máquina de indentación con muestras de $10 \times 10 \times 0,3 \mathrm{~mm}$ a temperaturas de 650,675 y $700^{\circ} \mathrm{C}$ con cargas de 199 a $512 \mathrm{~N}$. Las curvas de termofluencia del ensayo mostraron las tres etapas características observadas en el ensayo convencional de tensión. Asimismo, las principales relaciones de termofluencia entre parámetros como velocidad de termofluencia, esfuerzo, tiempo de ruptura y temperatura se observaron en los parámetros correspondientes al ensayo de indentación, lo que permitió caracterizar el comportamiento de termofluencia en este acero. El mecanismo y la energía de activación del proceso de deformación en la termofluencia corresponden al deslizamiento de los límites de grano y la difusión a través de los mismos, respectivamente, lo cual causó la fractura intergranular en las muestras ensayadas.

PALABRAS CLAVE: Acero inoxidable austenítico 316; Comportamiento de termofluencia; Ensayo de termofluencia de indentación

Copyright: (C) 2015 CSIC. This is an open-access article distributed under the terms of the Creative Commons Attribution-Non Commercial (by-nc) Spain 3.0 License.

\section{INTRODUCTION}

Austenitic stainless steels are widely used in industrial applications at high temperatures because of its high corrosion resistance and creep strength.
The evaluation of creep characteristics are usually carried out by the conventional uniaxial creep test at selected values of temperature and stresses. The results of this test are used to determine design parameters such as the rupture life (Marshal, 1984). 
However, the application of the conventional test has some disadvantages because of its specimen size, which cannot be extracted from in-service components. Thus, the use of miniaturized mechanical testing has become a necessity to manage the evaluation of properties in materials.

The Small Punch (SP) test is a miniaturized mechanical testing method which employs a specimen size of about $10 \times 10 \times 0.5 \mathrm{~mm}$. This specimen is clamped in a fixture and punched, up to several millimeters, with a spherical indenter (Saucedo-Muñoz et al., 2003; Cuesta et al., 2010). The plastic deformation process of the material is characterized by monitoring the tip displacement of the specimen as a function of the applied force. The specimen size is a considerable advantage, compared to the conventional test, in order to evaluate the mechanical properties of specimens located in the industrial inservice components and even from small areas such as the heat affected zones in the welds. This specimen size causes a minor damage in the industrial components. Moreover, the SP test is a simple testing method with a relatively low cost. The SP testing method can be applied to evaluate mechanical properties in extreme conditions; that is, the SP test can be carried out at cryogenic temperatures, room temperatures and even at high temperatures. The SP test specimen are under a biaxial-stress state, which could be more suitable than the uniaxial stress of most conventional tests to evaluate the material properties in similar stress states of the actual inservice components.

The evaluation of the microstructural condition of high temperature components is often carried out non-destructively by indirect methods such as metallurgical replication or hardness testing. These procedures may provide useful guidance regarding the damage state, but there is frequently a need for direct measurement of creep and other mechanical properties. The required testing then needs the removal of material from specific component locations. Nevertheless, the removal of a sample large enough to produce a typical uniaxial test specimen has the drawback that a weld repair must normally be carried out. This repair may adversely affect the structural integrity of the remaining structure. Therefore, the use of small specimens in the evaluation of the creep behavior is essential.

Several studies with small punch creep test have been carried out to evaluate successfully the creep properties in different steels. For instance, Parker and James (1994) utilized disc specimens to evaluate the creep properties in low alloy ferritic steel. Komazaki et al. (2000) applied the SP creep testing technique using miniaturized specimens to evaluate the creep properties and material deterioration in tungsten-alloyed 9\% Cr ferritic steel. SaucedoMuñoz et al. (2002) used the small punch creep test to evaluate successfully the creep properties for in-service boiler tubes of SUS 316 HTB austenitic stainless steel. Hou et al. (2013) determined the creep properties in pearlitic steel by the small punch creep test. Izaki et al. (2009) applied this test for the creep life assessment in boiler pipe steels. Evans and Wang (2008) used numerical methods for analyzing the small punch creep test. Chen et al. (2010) employed the finite element method for the analysis of this text to obtain creep parameters. Komazaki et al. (2009) analyzed the influence of different testing factors on this test. Finally, Mathew et al. (2014) tested the creep resistance of nitrogen-containing austenitic stainless steels by this miniature testing method. The main results of these studies were able to describe the basic creep behavior described by a conventional uniaxial text, as well as to follow the basic creep relations used to characterize the creep behavior. Furthermore, these works have been able to stablish relationships between the creep parameters of small punch creep test and those corresponding to the conventional creep test in order to evaluate more accurately the damage originated under creep conditions in the industrial components.

This work has the purpose to show the application of the small punch creep test on the evaluation of creep behavior in a 316 austenitic stainless steel at temperatures between 650 and $700{ }^{\circ} \mathrm{C}$, since these temperatures are common during the operation of different industrial components.

\section{EXPERIMENTAL DETAILS}

A 316 austenitic stainless steel was used to study the creep behavior and its chemical composition is as shown in Table 1. The condition of this steel is asreceived, solution treated and quenched. The small punch creep test was carried out using a creep tester shown in Figure 1, see for more details Komazaki et al. (2000). This consists of a striker bar, alumina puncher, alumina ball of $2.4 \mathrm{~mm}$ diameter, specimen holder, with associated instrumentation for loading, oxidation-proofing and data acquisition. Specimens of $10 \times 10 \times 0.3 \mathrm{~mm} \pm 0.002 \mathrm{~mm}$ were spark cut. This thickness was selected in order to reduce the testing time. The specimen surface was ground from both sides using abrasive papers up to grade 1000 grit. The test load was kept constant by hanging a weight through a lever. Tests were conducted in duplicate at $650{ }^{\circ} \mathrm{C}$ with loads of 234 , 286,338 and $408 \mathrm{~N}, 675^{\circ} \mathrm{C}$ using loads of 234,338 and $512 \mathrm{~N}$ and $700{ }^{\circ} \mathrm{C}$ employing loads of 199 and $234 \mathrm{~N}$ under an argon atmosphere. These testing temperatures were chosen because they correspond

TABle 1. Chemical composition of the steel

\begin{tabular}{lcccccc}
\hline Element & $\mathbf{C}$ & $\mathbf{S i}$ & $\mathbf{M n}$ & $\mathbf{N i}$ & $\mathbf{C r}$ & $\mathbf{M o}$ \\
\hline WT. $\%$ & 0.08 & 0.45 & 1.50 & 12.90 & 16.50 & 2.10 \\
\hline
\end{tabular}




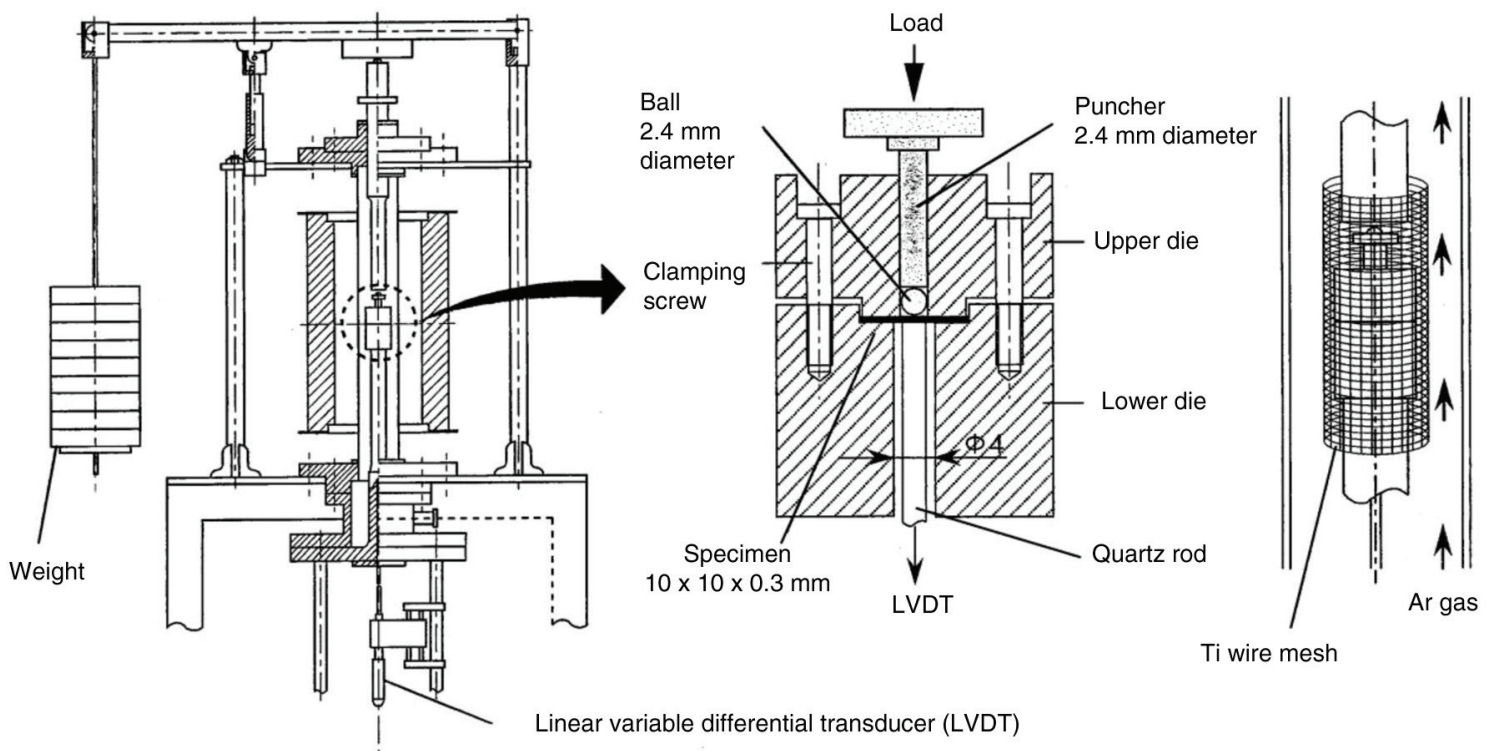

FIgURE 1. Schematic illustration of apparatus for the SP creep testing method.

to the operation temperatures used in several industrial components (Marshal, 1984). The load levels at each temperature were chosen in order to reproduce the main characteristics of creep curves. The deflection of specimen was monitored in the central part by measuring the displacement of a quartz rod using a linear variable differential transducer. The tested specimens and fracture surfaces were observed with a SEM at $15 \mathrm{kV}$. The microstructural characterization of these samples was carried out by metallographic preparation, etching with Villela's reagent and then observed in a SEM at $15 \mathrm{kV}$. Precipitates were extracted by electrochemical dissolution of the austenite matrix using a solution of $10 \mathrm{vol} . \% \mathrm{HCl}$ in methanol at $6 \mathrm{~V}$ (d.c.). Residues were analyzed in an X-ray diffractometer with a monochromated $\mathrm{Cu}$ $\mathrm{K} \alpha$ radiation.

\section{RESULTS}

\subsection{Creep behavior}

The typical plots of central deflection $\delta$ versus time for the 316 austenitic stainless steel, after SP creep testing at 650,675 and $700{ }^{\circ} \mathrm{C}$, are shown in Figure 2 (a-c), respectively. The SP creep test curves are very similar to those of the conventional uniaxial creep test. Three stages can be clearly observed in curves for all the tested specimens. That is, the primary creep is recognized by the decreasing slope of the creep curve; the secondary-stage creep with a nearly constant creep rate and the accelerating tertiary-stage creep that marks the final fracture at rupture time $t_{r}$. It is evident from these figures that the SP creep test curves change its shape as a function of the testing load in a similar manner as in the uniaxial creep tests. Figure 2 (a-c) shows clearly that the length of the secondary-creep stage and rupture time $t_{r}$ decrease as the testing load increases. These also decrease with testing temperature for the same testing load. With decreasing loads, the two first stages become clearly defined, usually at the expense of the tertiary stage.

Figure 3 (a-c) shows the plots of the creep deflection $\delta_{c}$ as a function of the creep life fraction $t / t_{r}$ for the steel tested at 650,675 and $700{ }^{\circ} \mathrm{C}$, respectively, corresponding to curves shown in Figure 2 (a-c), respectively. The creep deflection was defined by the following equation:

$$
\delta_{\mathrm{c}}=\delta-\delta_{\mathrm{i}}
$$

where $\delta$ is the central deflection and $\delta_{1}$ the instantaneous deflection, which corresponds to the elastic and plastic strain immediately after loading. The creep deflection is practically independent of testing load at $650{ }^{\circ} \mathrm{C}$. In contrast, the creep deflection increases with the test load at testing temperatures of 675 and $700{ }^{\circ} \mathrm{C}$, being the latter the one which has the highest central deflection.

\subsection{Morphology and fracture surface of small punch creep specimens}

The morphology of small punch is shown in Figure 4 ( $\mathrm{a}$ and $\mathrm{b}$ ) for the specimens tested at $650{ }^{\circ} \mathrm{C}$ and $700{ }^{\circ} \mathrm{C}$ with a load of $234 \mathrm{~N}$. In general, all of the SP-C specimens showed a hemispherical specimen surface and the fracture occurred along the circumference, where the equivalent strain was the largest. The difference in failure mode between these specimens can be appreciated by observing 

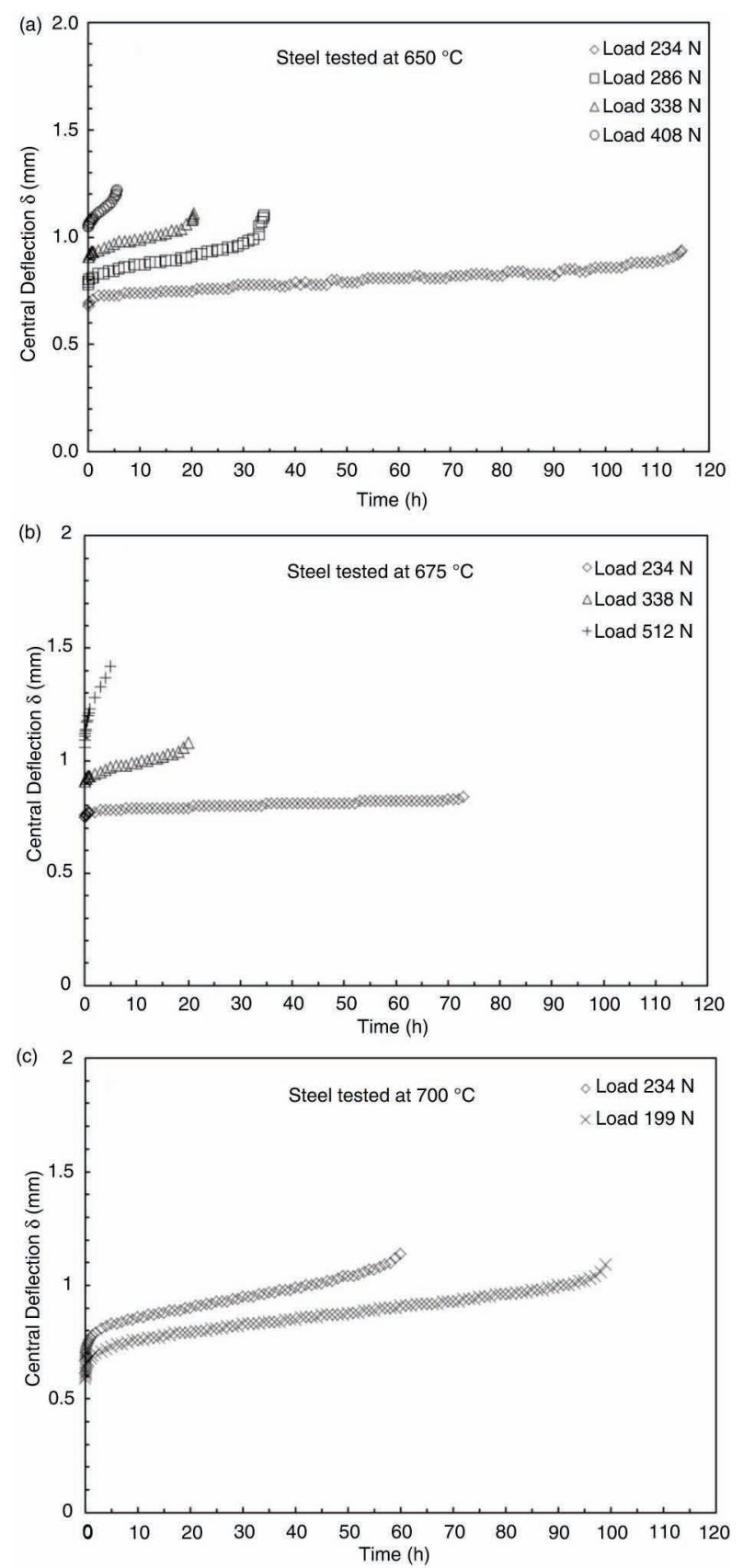

Figure 2. Curves of SP creep test for steel tested at: (a) 650 , (b) 675 and (c) $700{ }^{\circ} \mathrm{C}$.

the specimen cross-section near the fracture surface, as will be shown later. The deformation process of specimens takes place first by the bending of specimen, where a rapid increase in the contact area between the ball and the specimen surface occurs, and then the stretching of the contact area, where the increase in central deflection is predominant.

The failure morphology for the tested steel, corresponding to Figure 4 ( $a$ and $b$ ), is shown in
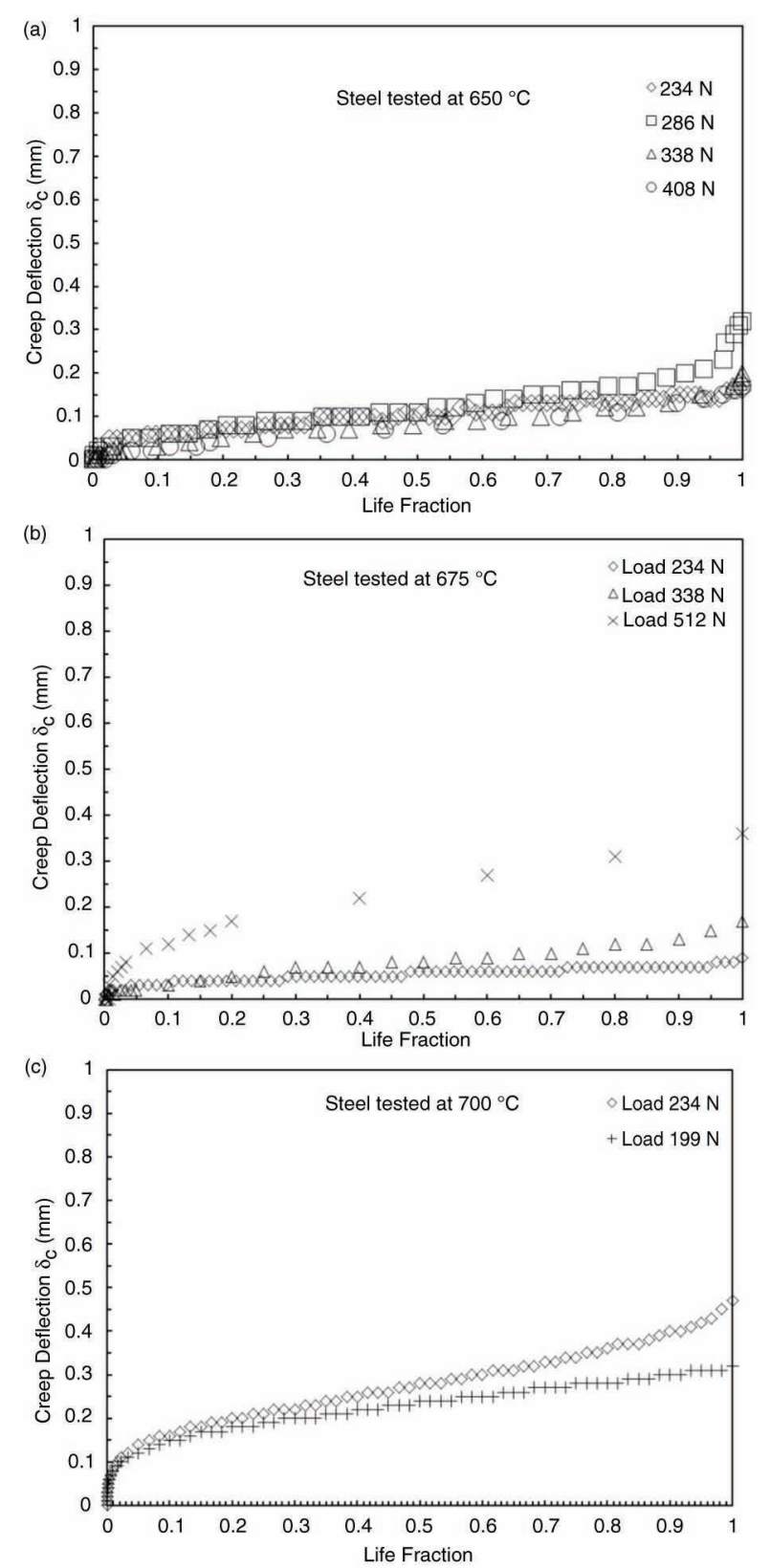

FIGURE 3. Creep deflection curves versus creep life fraction for steel tested at: (a) 650 , (b) 675 and (c) $700{ }^{\circ} \mathrm{C}$.

Figure 5 ( $\mathrm{a}$ and $\mathrm{b}$ ), respectively. These photographs were taken using the cross-section of the SP creep test ruptured specimens. An intergranular failure mode was observed to occur for this specimen with a small decrease in thickness (Fig. 5a). The failure mode occurred through the grain boundaries of austenite. This specimen shows a small reduction in thickness which suggests a low ductility. This characteristic of brittle fracture is responsible for the lower ductility of this steel during the small creep testing at $650{ }^{\circ} \mathrm{C}$. On the other hand, the failure mode for the specimen tested at $700{ }^{\circ} \mathrm{C}$ with a load 

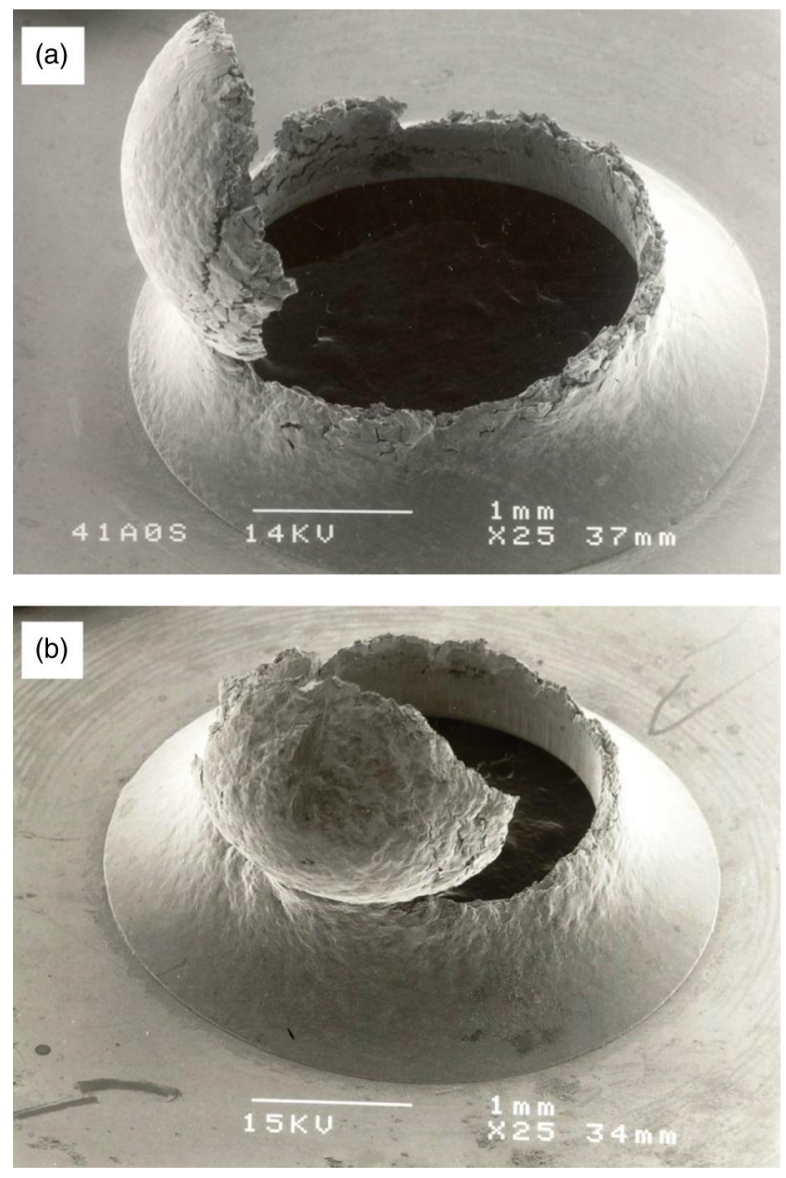

FIGURE 4. SEM photographs of small punch creep test specimens after testing at: (a) 650 and (b) $700{ }^{\circ} \mathrm{C}$ with a load of $234 \mathrm{~N}$

of $234 \mathrm{~N}$ occurred in a ductile intergranular manner (Fig. 5b). This specimen shows a great reduction in thickness which involves more ductility. This type of failure mode was observed to occur in the specimen tested at 675 and $700{ }^{\circ} \mathrm{C}$ independently of the testing load level.

\subsection{Microstructural characterization of small punch creep specimens}

The microstructure of the as-received steel is shown in Figure 6a, which shows the presence of the austenite matrix without any trace of precipitation. In contrast, the SEM micrographs of small punch creep specimens tested at 650 and $700{ }^{\circ} \mathrm{C}$ with a load of $234 \mathrm{~N}$ show mainly precipitation on grain boundaries, Figure 6 (b and c) respectively; however, a few precipitates are also observed within the austenite grains. The grain boundary precipitation is more abundant for the specimen tested at $700{ }^{\circ} \mathrm{C}$. The $\mathrm{X}$-ray diffraction pattern of the residues, extracted from steel aged at $650{ }^{\circ} \mathrm{C}$ for 40 hours, is shown in Figure 7 and it indicates that all the diffraction peaks correspond to $\mathrm{Cr}_{23} \mathrm{C}_{6}$ carbide which is in agreement
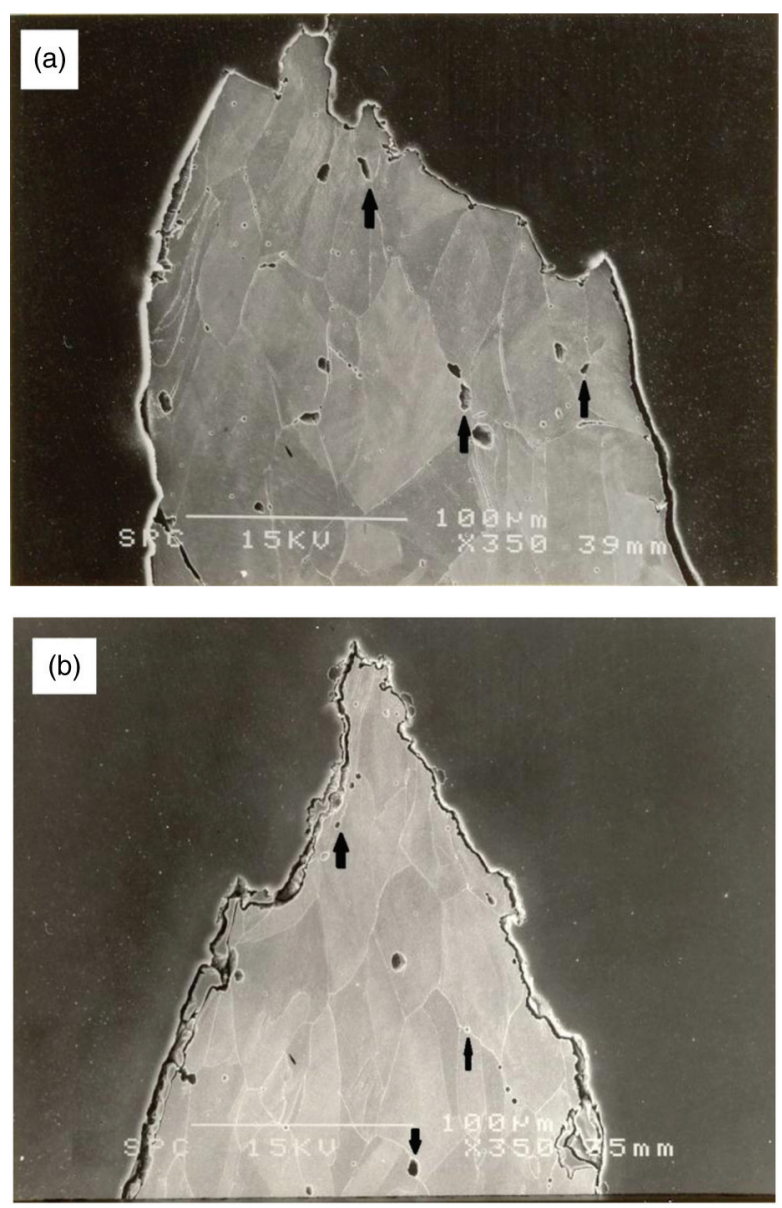

FIGURE 5. SEM photographs of the failure morphology of small punch creep after testing at: (a) 650 and

(b) $700{ }^{\circ} \mathrm{C}$ with a load of $234 \mathrm{~N}$

with the Time-Temperature-Precipitation (TTP) reported in the literature (NRIM, 2003). This diagram predicts first the grain boundary precipitation of $\mathrm{Cr}_{23} \mathrm{C}_{6}$ carbide and then followed by the precipitation of the $\eta\left(\mathrm{Fe}_{2} \mathrm{Mo}\right)$ phase in steel specimens aged at temperatures between 650 and $750{ }^{\circ} \mathrm{C}$ for times of 1 to 1000 hours.

\section{DISCUSSION}

\subsection{Creep behavior}

It was stated in the previous section that the main characteristics of the conventional uniaxial creep test are reproduced adequately with the small punch creep test (Fig. 2a-c). That is, the three stages of creep are clearly identified. For instance, Figure 8 a shows the plot of small creep rate $\dot{\delta}$ against time and it can be seen that the creep rate decreases with time, and then reaches its minimum value and finally increases rapidly until the rupture takes place, according to the three stages of creep. The minimum small punch creep rate decreases with the decrease in load. 

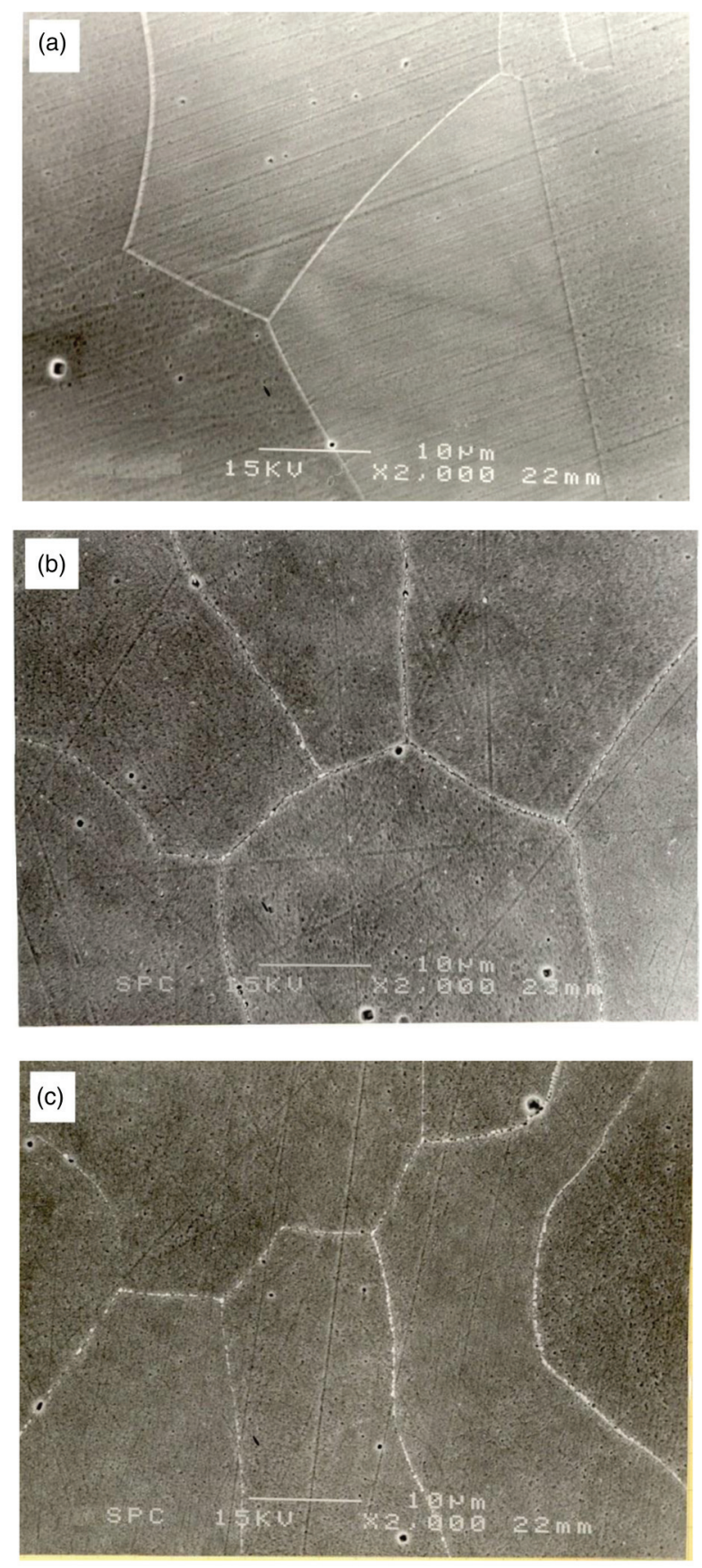

FIGURE 6. SEM micrographs of: (a) the as-received steel, the specimens after testing at: (b) 650 and (c) $700{ }^{\circ} \mathrm{C}$ with a load of $234 \mathrm{~N}$.

Figure $8 \mathrm{~b}$ shows the plot of the testing load against time to rupture $t_{r}$ for the steel tested at $650{ }^{\circ} \mathrm{C}$ and it can be noticed that the time to rupture decreases with the increase in the testing load level. This behavior has been reported (Dobes and Milicka, 2009) to follow the following power law relationship:

$$
t_{r}=\mathrm{A}_{c} \sigma^{m}
$$

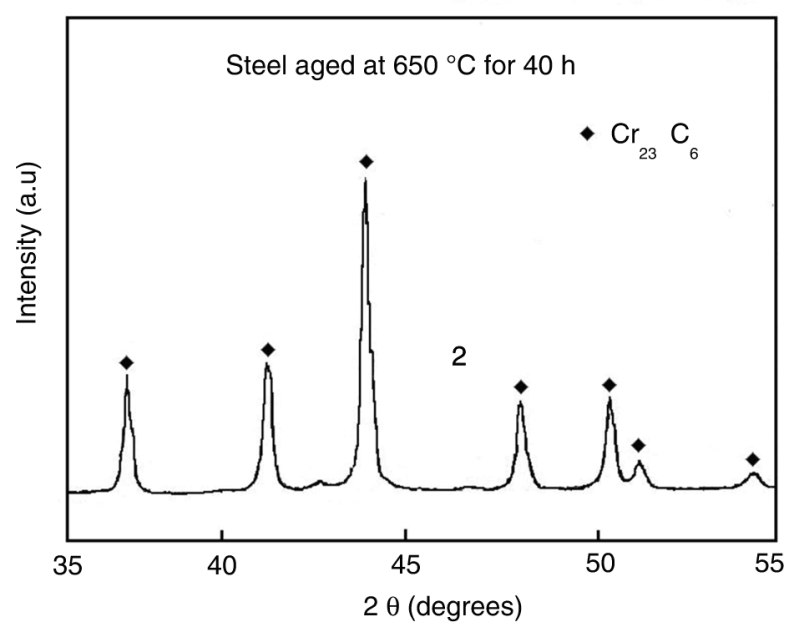

FIGURE 7. XRD pattern of the extracted residues from steel aged at $650^{\circ} \mathrm{C}$ for 40 hours.
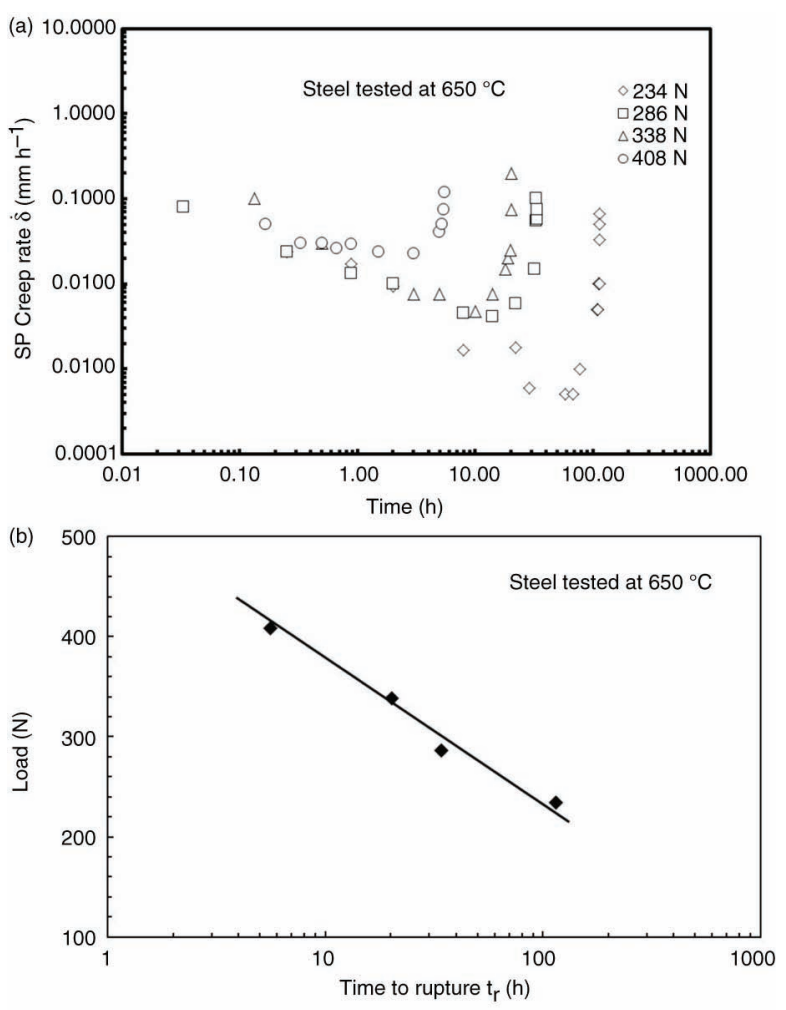

FIGURE 8. Plots of the: (a) SP creep rate and (b) testing load versus time for steel tested at $650{ }^{\circ} \mathrm{C}$.

where $A_{c}$ is a constant value. In the case of the small punch test of this work, a similar relation was observed to be followed and it can be expressed as follows:

$$
t_{r}=\mathrm{A}_{s} F^{-0.2}
$$

Taking data from reference (NRIM, 1978), the exponent $m$ of Eq. (2) was determined to be about 
-0.21 for the conventional uniaxial test, which is in good agreement with the value of -0.2 for Eq. (3). This type of relation for the small punch creep test has been reported to occur in other works (Dobes and Milicka, 2009).

All the above characteristics are commonly observed in the creep curves corresponding to the conventional creep test.

Creep is a thermally activated process and is expected to follow an Arrhenius-type expression with a characteristic activation energy $Q$ for the rate-controlling mechanism. The power law can be written as follows (Komazaki et al., 2000):

$$
\dot{\varepsilon}=A_{0} \sigma^{n} \exp (-Q / R T)
$$

where $A_{0}$ and $n$ are constant, $\dot{\varepsilon}$ the creep rate at the secondary stage, $\sigma$ the stress and $\mathrm{R}$ the universal gas constant.

The exponent $n$ can be determined from the slope of a straight line resulting in the plot of creep rate against stress. In this work, the small punch creep rate $\delta$ at the secondary stage and load $F$ were used instead of the creep rate $\varepsilon$ and the stress $\sigma$, as shown in Figure $9 \mathrm{a}$. The load exponent $n_{S P-C}$ was determined to be about 4.7. That is, Eq. (4) can be rewritten for the small punch creep test as follows:

$$
\dot{\delta}=A_{S P} F^{4.7}
$$

where $A_{S P}$ is a constant. Equation (5) has been shown to be followed by the small punch creep test in several works (Parker and James, 1994; Komazaki et al., 2000; Saucedo-Muñoz et al., 2002). In general, a small $n$ value, $3-5$, indicates that the creep deformation process is controlled by a grain boundary sliding. On the contrary, a large $n$ value, $8-12$, is present for a transgranular-controlled deformation process (Viswanathan, 1989). Thus, the $n_{S P-C}$ values, determined in this work, suggest that the SP creep test ruptures are controlled by the grain-boundary sliding. This result shows a good agreement with the failure mode observed in the SP creep tested specimens, (Fig. 5a and b). Additionally $n$ values of about 5 have been reported (Rieth et al., 2004; Saucedo-Muñoz et al, 2002) for the conventional creep test at temperatures of $650-750{ }^{\circ} \mathrm{C}$ in 316 type austenitic stainless steels.

It is well known and accepted that there is a relationship between the creep rate and the time to rupture, $t_{r}$, known as the Monkman-Grant relationship (Dieter, 1988) which states that the minimum creep rate $\dot{\varepsilon}$ is inversely proportional to the failure life:

$$
\log t_{r}+C \log \dot{\varepsilon}=K
$$

where $C$ and $K$ are constant for a given alloy. Figure $9 \mathrm{~b}$ shows the log-log plot of the small punch creep rate and the time to rupture and a linear
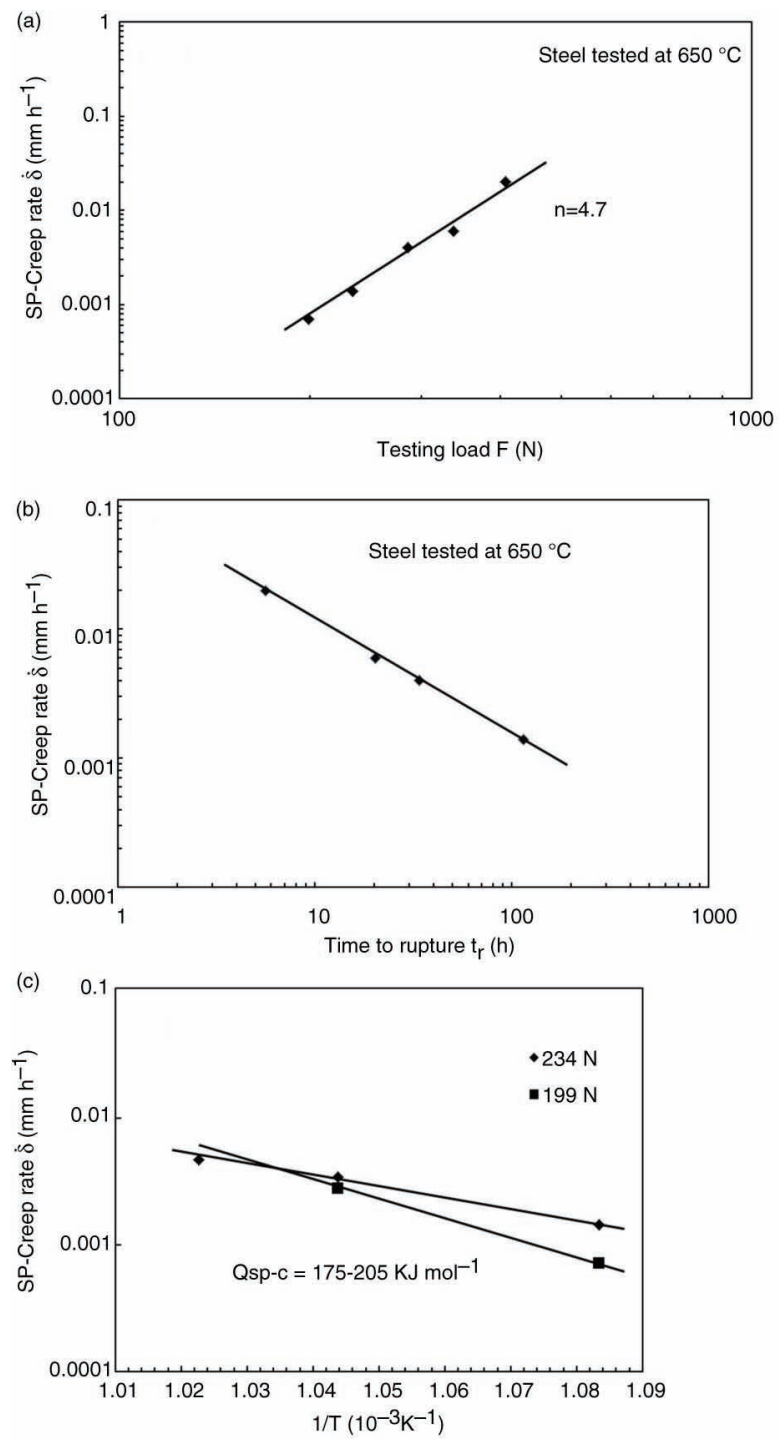

FIGURE 9. Plots of the SP creep rate versus: (a) testing load, (b) time to rupture and (c) inverse of temperature.

relationship can be observed which shows that the Monkman-Grant relationship states for this case and it is as follows:

$$
\log t_{r}-1.1384 \log \dot{\delta}=-1.1986
$$

This type of expression has been reported to be followed in the evaluation of creep properties for different materials by the small punch creep tests (Hou et al., 2013).

The temperature dependence of the small punch creep behavior for testing loads of 199 and $234 \mathrm{~N}$ is shown in Figure 9c. The apparent activation energy for the small creep deformation,

$\mathrm{Q}_{\text {SP-C }}$, can be obtained from the slope of the straight lines in this figure and it was determined to be about $175-205 \mathrm{~kJ} \mathrm{~mol}^{-1}$. The data points in Figure 9c 
seem to be not enough; however, the activation energy for the lattice and grain boundary diffusion has been reported (Frost and Ashby, 1982) to be 250 and 160-200 kJ mol ${ }^{-1}$, respectively. This comparison suggests that the activation energy of this work is close to that corresponding to the grain boundary diffusion.

\subsection{Creep mechanism}

The $n_{S P-C}$ value of about 5 indicates that the grain boundary sliding is the main deformation process during the small punch creep test at temperatures of 650,675 and $700{ }^{\circ} \mathrm{C}$. Besides, the activation energy, $175-205 \mathrm{~kJ} \mathrm{~mol}^{-1}$, for the deformation process is similar to that reported for the activation energy of grain boundary diffusion. These characteristics are in good agreement with the intergranular failure observed in present work specimens (Fig. 5a and b). Furthermore, it can be observed the presence of round or elliptical cavities (see for instance some of them indicated by arrows in these figures), formed in the grain boundaries (r-type cracks), which are usually associated with grain boundary sliding (Marshal, 1984).

It has been reported (Marshal, 1984) that the creep behavior by the conventional test at $600{ }^{\circ} \mathrm{C}$ that the creep rate of the previously aged 316 steel is much faster that of the solution treated or unaged steel. Besides, the failure mode was trangranular in the aged steel and intergranular in the solution treated steel. An appropriate explanation for this behavior is that the coarse grain boundary precipitation in the aged steel prevents the grain boundary sliding and so inhibits the intergranular fracture. In contrast, the starting of grain boundary precipitation reduces the concentration of carbon or solid solution elements thus minimizing the pinning of dislocations during creep. Additionally, the regions adjacent to grain boundaries may be denuded in solute, which makes them weaker and susceptible to local plastic deformation in an intergranular way. Figure 6 (b and c) shows a very fine precipitation of carbides which seems to be not enough to prevent the grain boundary sliding in the present work. Furthermore, several studies (SaucedoMuñoz et al., 2002) have reported that the exponent $n$ value changes to $8-12$ for trangranular-controlled deformation process in the aged 316 type steel.

\section{CONCLUSIONS}

The small punch creep test was applied to characterize the creep behavior in a 316 type austenitic steel and the conclusions are as follows:

- The small punch creep test enables us to reproduce the main characteristics observed in the creep curve of the conventional uniaxial test, as well as the main relationships between creep parameters.
- The creep mechanism of 316 type steel at $650{ }^{\circ} \mathrm{C}$ involves the grain boundary sliding as indicated by the exponent $n$ value of about 5 and the intergranular failure mode observed in the tested small punch creep specimens.

- The activation energy for the deformation process was determined to be about $175-200 \mathrm{~kJ} \mathrm{~mol}^{-1}$ which is close to the value reported for grain boundary diffusion.

\section{ACKNOWLEDGEMENTS}

The Authors wish to acknowledge financial support from SIP and CONACYT.

\section{REFERENCES}

Chen, J., Wha Ma, Y., Bong Yoon, K. (2010). Finite element study for determination of material's creep parameters from small punch test. J. Mech. Sci. Tech. 24 (6), 1195-1201. http://dx.doi.org/10.1007/s12206-010-0327-2.

Cuesta, I.I., Alegre, J.M., Lacalle, R. (2010). Determination of the Gurson-Tvergaard damage model parameters for simulating small punch tests. Fatigue Fract. Eng. Mater. Struct. 33 (11), 703-713. http://dx.doi.org/10.1111/j.14602695.2010.01481.x

Dieter, G.E. (1988). Mechanical Metalurgy, Mc Graw-hill, New York.

Dobes, F., Milicka, K. (2009). Application of creep small punch testing in assessment of creep lifetime. J. Mater. Sci. Eng. A 510-511, 440-443. http://dx.doi.org/10.1016/j. msea.2008.04.087.

Evans, M., Wang, D. (2008). The small punch creep test: some results from a numerical model. J. Mater. Sci. 43 (6), 1825-1835. http://dx.doi.org/0.1007/s10853-007-2388-x.

Frost, H.J., Ashby, M.F. (1982). Deformation-mechanism Maps, Pergamon Press, Oxford.

Hou, F., Xu, H., Wang, Y., Zhang, L. (2013). Determination of creep property of $1.25 \mathrm{Cr} .25 \mathrm{Mo}$ pearlitic steels by small punch tests. Eng. Fail. Anal. 28, 215-221. http://dx.doi. org/10.1016/j.engfailanal.2012.10.004.

Izaki, T., Kobayashi, T., Kumsumuto, J., Kanaya, A. (2009). A creep life assessment method for boiler pipes using small punch test. Int. J. Pres. Ves. Pip. 86 (9), 637-642. http:// dx.doi.org/10.1016/j.ijpvp.2009.04.005.

Komazaki, S., Hashida, T., Shoji, T., Suzuki, K. (2000). Development of small punch tests for creep property measurement of tungsten-alloyed $9 \% \mathrm{Cr}$ ferritic steels. J. Therm. Anal. 28, 249-256. http://dx.doi.org/10.1520/ JTE12250.

Komazaki, S., Kato, T., Kohno, Y., Tanigawa, H. (2009). A study on influence factors of small punch creep test by experimental investigation and finite element analysis. Mater Sci. Eng. A 510-511, 229-233. http://dx.doi.org/10.1016/j. msea.2008.04.132.

Marshal, P. (1984). Austenitic stainless Steels Microstructure and Properties, Elsevier, London.

Mathew, M. D., Ganesh Kumar, J., Ganesan, V., Laha, K. (2014). Small punch creep studies for optimization of nitrogen content in 316LN SS for enhanced creep resistance. Met. Mater. Trans. A 45 (2), 731-737. http://dx.doi.org/10.1007/ s11661-013-2027-x.

NRIM (1978). Creep Data Sheet No. 6A, National Research Institute for Metals, Tokyo, Japan.

NRIM (2003). Metallographic Atlas of Long-term Crept Materials No. $M-2$, National Research Institute for Metals, Tokyo, Japan.

Parker, J.D., James, J.D. (1994). Creep behaviour of miniature disc specimens of low alloy steel, development in a progressing technology. ASME 279, 167-172. 
Rieth, M., Falkenstein, A., Graf, P., Heger, S., Jäntsch, U., Klimiankou, M. Materna-Morris, E. Zimmermann, H. (2004). Creep of The Austenitic Steel $316 L(N)$ - Experiments and Models-, Forschungszentrum Karlsruhe $\mathrm{GmbH}$, Karlsruhe, Germany.

Saucedo-Muñoz, M.L., Komazaki, S., Takahashi, T., Shoji, T. (2002). Creep property measurement of service-exposed SUS 316 austenitic stainless steel by the small punch creeptesting technique. J. Mater. Res. 17 (8), 1945-1953. http:// dx.doi.org/10.1557/JMR.2002.0288.
Saucedo-Muñoz, M.L., Komazaki, S., Hashida, T., Shoji, T., Lopez-Hirata, V.M. (2003). Aplicación del ensayo miniatura de embutido para la evaluación de la tenacidad a temperaturas Criogénicas de Aceros Inoxidables Austeníticos Envejecidos Isotérmicamente. Rev. Metal. 39, 378-386. http://dx.doi.org/10.3989/revmetalm.2003.v39.i5.350.

Viswanathan, R. (1989). Damage Mechanism and Life Assessment of High-Temperature Components. ASM International, Metals Park, Ohio. 